\title{
Las pandemias: el COVID-19
}

\section{Pandemics: COVID-19}

\section{Pablo Kuri-Morales*}

Práctica Privada, Ciudad de México, México

El solo mencionar la palabra "pandemia» genera una sensación de gravedad e incluso de miedo. La Organización Mundial de la Salud (OMS) define pandemia como «la propagación mundial de una nueva enfermedad ". A lo largo de la historia hemos enfrentado un número considerable de pandemias. Baste recordar algunas que se han presentado a través de los siglos y que no solo han tenido un impacto sanitario, sino que también han cambiado la política, la economía y, al convertirse en grandes amenazas para la salud, han hecho que se desarrollen acciones de salud pública que hoy parecen normales, pero que en su momento fueron verdaderos hitos. Imaginemos la Europa del siglo XIV, pensemos en las condiciones sanitarias, el manejo de residuos y el desconocimiento de los agentes causales de la enfermedad; es en ese contexto donde se desarrolla lo que hoy entendemos como cuarentena.

Ledermann nos relata: «La cuarentena nació en 1374, con el edicto de Reggio, ciudad de Módena, Italia. En realidad, fue un cordón sanitario, pues el término cuarentena derivó en término marítimo, aplicándose un período de aislamiento a los buques que llegaban de puertos de mala fama médica. Este período llevaba implícita la idea del período de incubación. El primer puerto en que se decretó cuarentena (que fue solo treintena: luego se ampliaría) fue Ragusa (hoy Dubrovnik, Bosnia-Herzegovina, sobre el Adriático) en 1377. Seis años después, Marsella aumentó el plazo a los cuarenta días»².
¿A qué tuvieron tanto miedo nuestros antepasados que les obligó a detener, al menos temporalmente, el flujo de mercancías y personas? A que resurgiera la llamada "peste negra» que azotó el mundo conocido entre los años 1347 y 1351, enfermedad causada por Yersinia pestis y transmitida por las pulgas que vivían en las ratas. Las estimaciones indican que mató al $30 \%$ de la población europea. ¡Sí! ¡Una tercera parte!

Pero esa no fue la primera pandemia de la historia: hay registros desde el año 430 a.C. de la llamada «plaga de Atenas»; en el año 166 de nuestra Era, la «peste Antonina» en Roma; en el año 525, la «peste de Justiniano" ocasionada por Y. pestis; en Japón, la viruela en el año 735 , que en estricto sentido no fue una pandemia, pero tuvo un gran impacto en la población japonesa; en 1458, la epidemia del «sudor inglés", que se sugiere fue ocasionada por el virus de la influenza; y otras más que culminan con la mal llamada «gripe española» de 1918-1919, que en realidad parece haberse originado en los Estados Unidos y no en España, ocasionada por el virus de la influenza y que se estima mató entre 40 y 100 millones de personas, y con las de 1957-1958 y 1968-1969, también ocasionadas por el virus de la influenza. Ya en este milenio, la primera pandemia fue en 2009, ocasionada por el virus de la influenza AH1N1, para la que el mundo y México ${ }^{3}$ se preparaban esperando la llegada del AH5N1, mucho mas letal que el que apareció finalmente aquel año.

\footnotetext{
Correspondencia:

*Pablo Kuri Morales

Heriberto Frías, 915, int. 310

Col. Del Valle, Del. Benito Juárez

Fecha de recepción: 30-03-2020

C.P. 03100, Ciudad de México, México

E-mail: kuripablo@yahoo.com

DOI: 10.24875/CIRU.20000234

Cir Cir. 2020;88(3):249-251

Contents available at PubMed www.cirugiaycirujanos.com 0009-7411/@ 2020 Academia Mexicana de Cirugía. Publicado por Permanyer. Este es un artículo open access bajo la licencia CC BY-NC-ND (http://creativecommons.org/licenses/by-nc-nd/4.0/).
} 
Aunque no declaradas oficialmente pandemias, no debemos olvidar los virus Ébola, Zika y Chikungunya, ni muchas otras enfermedades que matan a millones de seres humanos todos los años, como la tuberculosis y el paludismo, y que afectan a las poblaciones más pobres y vulnerables. También otras enfermedades desatendidas, como la mordedura por víboras y la picadura de alacrán, ocasionan miles de muertes e incluso discapacidad, pero al ocurrir con mayor incidencia en regiones como África - Asia no adquieren la atención que seguramente tendrían si ocurrieran en países occidentales.

Hoy, en la segunda década del milenio, estamos ante una nueva pandemia, la producida por la enfermedad denominada COVID-19, cuyo agente causal es un virus de la familia de los Orthocoronavirinae, comúnmente conocidos como coronavirus. Los coronavirus no son nuevos y producen enfermedad en mamíferos y aves, entre otras especies. En los humanos pueden ocasionar desde un resfriado común hasta enfermedades graves como el SARS, el MERS y ahora el COVID-19.

Cuando lean estas líneas ya habrán ocurrido muchas más cosas de las que comentaré, porque esta pandemia, así declarada por la OMS el 11 de marzo de 2020, avanza rápidamente, y porque, al ser una nueva enfermedad entre los humanos, todos los días se está conociendo algo nuevo sobre ella. Es materialmente inviable referir lo que leerán porque el número de fuentes consultadas es enorme.

Todo indica que el COVID-19 viene de los murciélagos, tuvo un paso intermedio en otro mamífero, el único que tiene escamas en vez de piel, que se llama pangolín y que en China es altamente apreciado, y que incluso por su comercio está en peligro de extinción, y de ahí pasó al ser humano. La historia comienza hacia finales de 2019 en Wuhan, China, donde se decribe un brote de una enfermedad respiratoria grave que se descubre que es producida por un coronavirus distinto al del SARS y el MERS. Algunas semanas después se denomina a la enfermedad COVID-19 (CO de corona, $\mathrm{VI}$ de virus y $\mathrm{D}$ de disease, y se agrega el 19 por ser el año de aparición) y también se pone nombre al virus que la produce: SARS CoV 2.

Con el paso de los días y las semanas, y conforme la enfermedad se dispersa, se confirman varios hechos: es una enfermedad que se transmite de humano a humano por contacto con la saliva de los enfermos, ya sea por vía aérea, por fomites o por contacto con superfices contaminadas con partículas virales. Se sabe también que, por su peso, el virus cae una vez exhalado en una distancia aproximada de un metro o metro y medio, y que dependiendo de la superficie en la que se encuentre puede sobrevivir desde algunas horas hasta varios días.

El período de incubación parece ser de entre $1 \mathrm{y}$ 14 días, con un promedio de 4-6 días para que aparezcan los primeros síntomas; de estos, los más frecuentes son fiebre, tos seca, casancio y dolores musculares 0 articulares, pero puede haber rinorrea, diarrea o algunos otros síntomas, como trastorno del olfato. La dificultad respiratoria es el síntoma de alarma, el cual al aparecer obliga al enfermo a ir al médico. Hoy sabemos que, del total de los infectados (y advierto que esto es un promedio que ha variado de país en país), el 18\% cursa sin síntomas, el $62 \%$ presenta síntomas leves, un $15 \%$ requiere atención hospitalaria y un $5 \%$ requiere cuidados críticos. Los enfermos presentan cuadros más graves y defunciones conforme avanza la edad, y si tienen algunas condiciones previas, como enfermedad cardiaca, hipertensión o diabetes, entre otras, tienen más probabilidades de presentar enfermedad grave.

De los enfermos, mueren cerca de un $5 \%$, aunque es muy posible que este porcentaje esté altamente sobreestimado, ya que el denominador utilizado para su cálculo no incluye a todos aquellos que se han infectado y que son asintomáticos o que por tener síntomas leves nunca acudieron a los servicios de salud.

Al momento en que estas líneas son escritas no hay vacuna y tampoco un tratamiento específico. Hay resultados de algunos estudios que se comienzan a publicar que suenan alentadores, pero aún no son definitivos en lo que a medicamentos se refiere. Entonces, no queda otra defensa contra el COVID-19 que las medidas básicas de higiene, como el lavado frecuente de manos con agua y jabón, toser o estornudar en el ángulo del brazo y el antebrazo, y el distanciamiento social, que implica el distanciamiento físico entre las personas.

Prevalecen varios debates, como el de realizar pruebas, pruebas y pruebas, o solo pruebas a sopechosos, contactos de casos confirmados o casos graves; o el uso de cubrebocas generalizado o solo en quienes tienen síntomas (todo parece indicar que los asintomáticos sí diseminan el virus y que los sintomáticos también lo hacen algunos días antes de que empiecen sus síntomas).

Aún no tenemos suficiente información para poder afirmar qué modelo de respuesta es el más efectivo, 
si el coreano, el chino, el alemán o el de los países nórdicos, es decir, los más restrictivos o los menos restrictivos. Sea cual sea el que termine siendo más efectivo, lo que se busca es "administrar» la epidemia, o sea, evitar que el número de casos graves llegue a los servicios de salud en un mismo momento, porque como ha ocurrido en Italia, en España y en algunos sitios de nuestro vecino del norte, el sistema de salud se ve rebasado.

Hay aún más preguntas que respuestas, conviene pensar en cómo estamos enfrentado esta pandemia en la era de las comunicaciones (¿cómo la estaríamos haciendo si no hubiera Whatsapp, Twitter, Facebook ni You Tube?), en lo individual y en lo social (¿lo estaríamos viviendo igual?). No hay duda de que el COVID-19 ha cambiado la vida, el día a día de millones de personas. Seguramente no acabará con la Humanidad, pero sí debe llevarnos a la reflexión sobre si los modelos económicos y de salud, y las acciones humanas, que están impactando en nuestro entorno, no deben ser revisados. EI COVID-19 pasará, pero vendrán nuevas enfermedades y deberíamos aprender las lecciones que esta nos deje para prepararnos mejor y aminorar los impactos en la salud y en otras esferas, como la económica.
Tomar decisiones en un entorno de tanta incertidumbre no es nada fácil; criticar desde fuera las decisiones tomadas es mucho más sencillo. Hoy deberíamos apuntalar las decisiones en la mejor evidencia disponible y entender que solo con la particpación de todos se puede hacer frente a desafíos como el del COVID-19, y comprender que el miedo se contagia más rápido que la enfermedad.

\section{Financiamiento}

El autor declara que no ha recibido ningún financiamiento para escribir este editorial.

\section{Conflicto de intereses}

El autor declara no tener ningún conflicto de intereses relacionado con el contenido del editorial.

\section{Bibliografía}

1. Alerta y respuestas mundiales (GAR). World Health Organization;2020 [Citado 28 de marzo 2020]. Disponible en: https://www.who.int/csr/disease/swineflu/frequently_asked_questions/pandemic/es/

2. Ledderman W. El hombre y sus epidemias a través de la historia. Rev Chil Infect Edición Aniversario. 2003;13-7.

3. Kuri-Morales $\mathrm{P}$, Betancourt $\mathrm{M}$, Velazquez $\mathrm{O}$, et al. Pandemia de influenza: la respuesta en México. Salud Pub Mex. 2006;48:72-9. 